\title{
25 Años de la presencia de Paulo Freire en tierras valencianas... De la esperanza a la espera
}

\section{Years of Paulo Freire's presence in valencian lands... From hope to waiting}

José A. Veiga Gómez ${ }^{1}$

Centro de Formación de Personas Adultas de Torrent [Valencia]

J.Antonio.Veiga@uv.es

ORCID ID: https:/ / orcid.org/0000-0001-8531-9659

\section{Resumen}

Se ofrece un estudio que permite contextualizar la conferencia que impartió Paulo Freire en Valencia en marzo de 1995, hace veinticinco años. Se realiza una aproximación a algunos de los hechos mediante una historia de vida elaborada a partir de experiencia vivida como director del seminario junto a las personas ponentes en esas jornadas de trabajo y con la suma de la importante documentación existente: programas, textos, fotografías, agendas, anotaciones, copias de escritos oficiales y oficiosos...Freire pronunció su conferencia dentro de un seminario que tuvo un gran éxito, al que se inscribieron más de 700 personas y que supuso un acontecimiento de primer orden en la historia educativa valenciana.

Palabras clave: Paulo Freire, formación de personas adultas, Educación, Sociología, historias de vida.

\section{Abstract}

A study is offered that helps to contextualize the conference given by Paulo Freire in Valencia in March 1995, twenty-five years ago. An approach is made to some of the facts by means of a life story elaborated from the experience lived as director of the seminar together with the speakers in those days of work and with the sum of the important existing documentation: programs, texts, photographs, agendas, notes, copies of official and unofficial writings...Freire gave his lecture as part of a very successful seminar, which was registered by more than 700 people and was a firstrate event in the history of education in Valencia.

Key words: Paulo Freire, adult education, Education, Sociology, life stories.

$1 \quad$ Director y profesor del Centro Público de Formación de Personas Adultas en Torrent [Valencia], profesor asociado de la Universidad de Valencia hasta el curso 2019-2020, Departamento de Didáctica y Organización Escolar. En 1995, asesor en materia de educación de personas adultas del conseller de Educación, Joan Romero. 


\section{Introducción}

En 2020 se ha cumplido el vigesimoquinto aniversario de la presencia de Paulo Freire en tierras valencianas. Participaba en el Seminario "La importancia estratégica de la formación de personas adultas en la Comunidad Valenciana" organizado por la sede local de la Universidad Internacional Menéndez Pelayo [UIMP], y llevado a cabo los días 30 y 31 de marzo de 1995 en el Palau de Pineda de Valencia, donde se ubica la institución. En el contexto del mismo Seminario, participó también en dos jornadas formativas en la Cámara de Comercio de Castellón y en el Aula de Cultura de la Caja de Ahorros del Mediterráneo de Alicante, los días 3 y 4 de abril, respectivamente.

En el Seminario, que tuve la fortuna de dirigir, participaron junto a Paulo Freire diferentes ponentes con destacadas aportaciones en el ámbito de la formación de personas adultas [FPA] y de las ciencias de la educación en general, de la sociología, de la formación ocupacional, de la gestión pública estatal en FPA, de la gestión política y social valenciana, del sindicalismo, de la empresa y del periodismo. La presentación en el acto inaugural fue realizada por el honorable conseller de Educación de la Generalitat Valenciana, Joan Romero², impulsor decidido del evento.

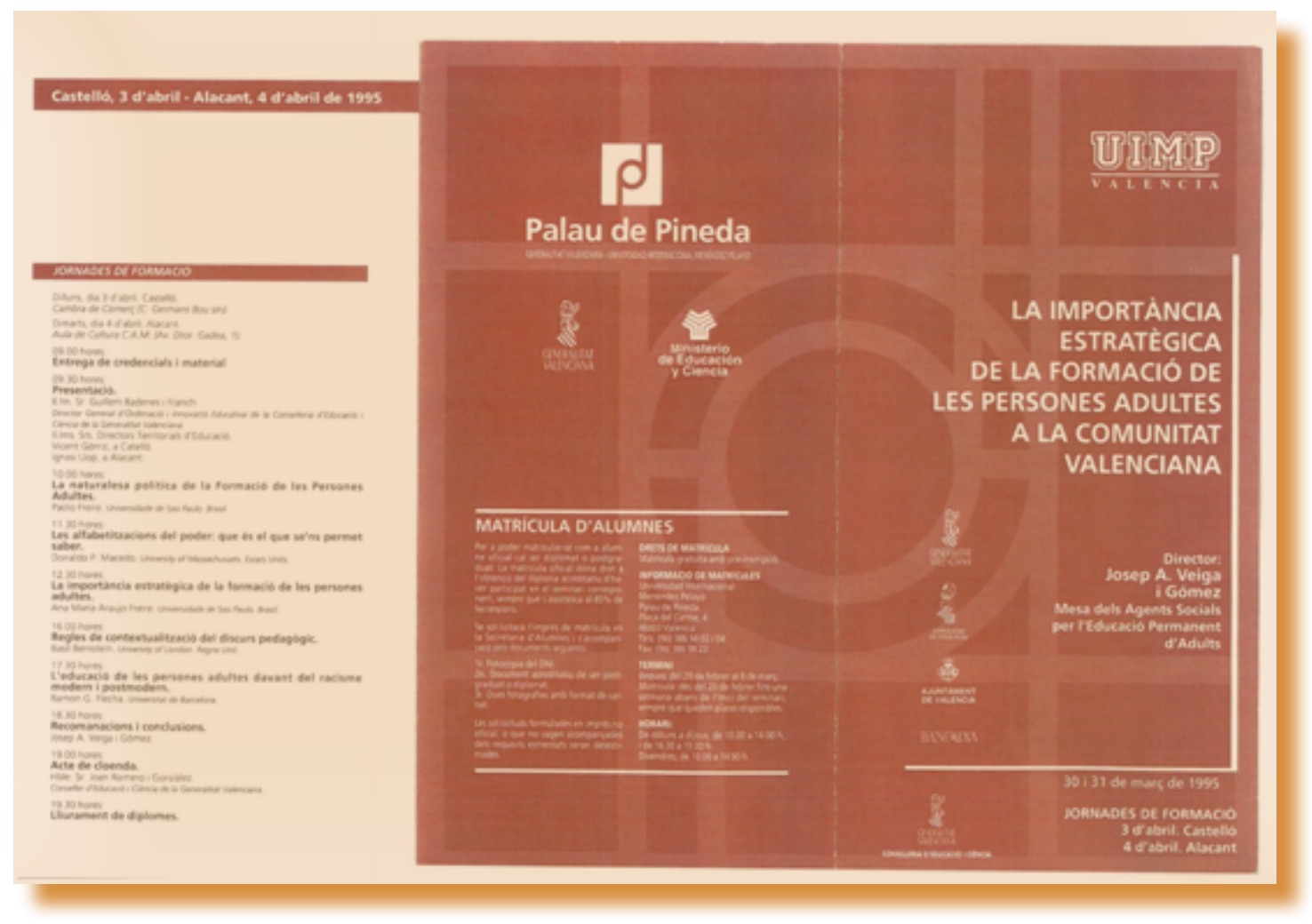

Fig. 1. Programa del Seminario La importancia estratégica de la formación de personas adultas en la Comunidad Valenciana. Portada.

$2 \quad$ Catedrático de Geografía Humana de la Universidad de Valencia, Departamento de Geografía. Entre 1993 y 1995 fue conseller de Educación y Ciencia de la Generalitat Valenciana. Durante su mandato, se aprobó la Ley 1/95 de 20 de enero, de la Generalitat Valenciana, de FPA. Fue el más destacado impulsor del Seminario "La importancia estratégica de la FPA en la Comunidad Valenciana”. Véase la entrevista que se realiza en este mismo número de la revista. 


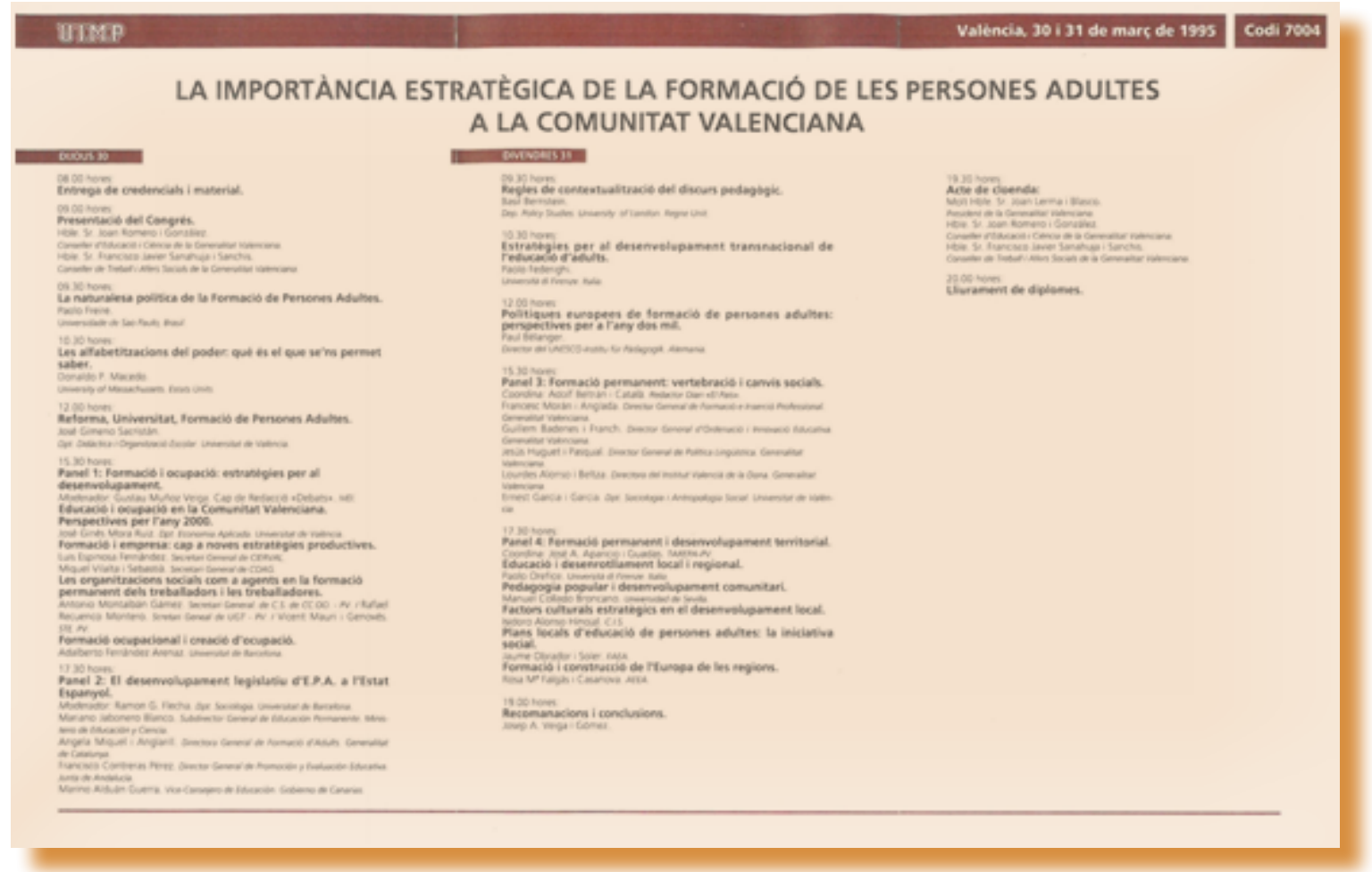

Fig. 2. Programa del Seminario Programa del Seminario La importancia estratégica de la formación de personas adultas en la Comunidad Valenciana. Tríptico.

En el Seminario se inscribieron más de 700 personas, un fenómeno inusual en la institución de acogida, que tensionó los servicios administrativos de la sede valenciana de la UIMP y que los responsables de entonces, dirigidos por Joaquín Azagra, resolvieron con extraordinaria eficiencia. La mayoría de personas participantes formaban parte de los diferentes colectivos docentes de la FPA valenciana (profesorado de la Conselleria de Educación, de la Diputación de Valencia, de los municipios y de entidades de iniciativa social sin ánimo de lucro]. También hubo presencia de alumnado participante en los centros de FPA, de profesorado y alumnado universitario, asesorías de educación de adultos de los Centros de Profesores [CEPs] y personal técnico de educación de las administraciones autonómica, provincial, local y estatal.

En las próximas páginas, trataremos de hacer una aproximación a lo que supuso aquel Seminario, a la presencia de Paulo Freire entre nosotros, al contexto que se vivía en unos momentos de notoria esperanza en el mundo de la FPA valenciana, pero también de incertidumbre por el previsible cambio político que se avecinaba y que sin duda afectaría a las políticas de formación de las personas adultas. Trataremos asimismo de aproximarnos a algunos de los hechos reconstruyendo "historias de vida" con la suma de la importante documentación existente: programas, textos, fotografías, agendas, anotaciones, copias de escritos oficiales y oficiosos... y las valiosas imágenes de la intervención de Paulo Freire y de todas las personas ponentes en aquellas jornadas de trabajo que, desde mi punto de vista, supusieron un acontecimiento de primer orden en la historia educativa valenciana.

Quiero agradecer la amable invitación de los profesores de la Universidad de Valencia José Beltrán, Francesc J. Hernàndez y Rosa Isusi a participar en esta importante tarea de indagación y conmemoración de la presencia de Paulo Freire entre nosotros y nosotras. En aquellos momentos, 
tuve la oportunidad de dirigir el Seminario y de coordinar su organización; también de participar, como asesor del conseller Joan Romero, en la coordinación de los trabajos de promulgación y primer desarrollo de la Ley Valenciana de FPA de 1995. A lo largo de mi vida profesional, aún activa, he podido llevar a cabo diferentes tareas de coordinación y gestión, en iniciativas sociales, en centros públicos de FPA y en el ámbito municipal. Pero, por encima de todo, he apreciado la docencia y he disfrutado desarrollándola, en escuelas de personas adultas y en la Universidad de Valencia como profesor asociado en el departamento de Didáctica y Organización Escolar. En palabras del propio Paulo Freire, creo ser profesor "en favor de la lucha constante contra cualquier forma de discriminación [...];en favor de la esperanza que me anima” [Freire, 1997].

Trabajar en formación de personas adultas a lo largo de cuarenta años me ha permitido tener un contacto diario con la realidad formativa de nuestros entornos cotidianos. Hacerlo además en un centro grande [el Centro Público de FPA de Torrent] situado en el área metropolitana de Valencia, con una amplia y dinámica oferta formativa, con equipos comprometidos y con más de mil quinientas personas participantes cada curso, me ha servido de constante estímulo en la tarea enormemente compleja de impulsar la formación de personas adultas y, dentro de ella,de trabajar prioritariamente contra la pobreza educativa, pobreza que presenta múltiples gradaciones, pero que relega a condiciones muchas veces extremas de exclusión social a quienes se hallan en las posiciones menos ventajosas.

Creo también haber tenido la suerte de ser testigo directo del proceso de mejora en los niveles formativos de la población adulta valenciana. He podido aportar mi minúsculo grano de arena en ese proceso de mejora, convencido de que con el esfuerzo de otros muchos construíamos una montaña firme... Se ha hecho mucho, muchísimo, pero la propia realidad nos recuerda insistentemente que aún queda mucha tarea pendiente y que sociedades como la nuestra necesitan sistemas sólidos de formación de personas adultas capaces de dar respuestas a los continuos y cambiantes retos en diferentes áreas de intervención.

A pesar de que las recomendaciones internacionales caminan en otra dirección, no son pocos quienes aún mantienen una visión básicamente compensadora de la FPA. Esta interpretación considera que la finalidad fundamental de la formación de personas adultas es la de corregir las deficiencias del sistema escolar ordinario y que, actuando decididamente en este, se previenen las insuficiencias hasta hacerlas casi desaparecer, con lo que sería redundante emplear recursos propios para sostener una red de actuaciones diferenciadas de FPA. Aunque legítima, no es esa la visión que personalmente comparto: para construir una verdadera sociedad del conocimiento, es requisito imprescindible crear una red estable de aprendizaje a lo largo de la vida que aumente significativamente la participación de las personas adultas en procesos de educación formal, no formal e informal. En esa red estable de aprendizaje a lo largo de la vida, los centros públicos de formación de personas adultas han tenido y tienen un papel excepcional.

He querido diferenciar tres apartados en esta aportación escrita. En el primero, hablaremos del contexto en el que se lleva a cabo el Seminario. En el segundo, nos referiremos al Seminario mismo, su organización, contenido y desarrollo, y reseñaremos algunas situaciones cotidianas vividas con algunas de las personas participantes, de manera singular con Paulo Freire. En el tercer apartado, que hemos creído oportuno designar como "De la esperanza a la espera: un desarrollo legislativo truncado", recuperaremos la línea contextual y trataremos de apuntar las principales expectativas que el amplio colectivo de FPA tenía entonces, y que siguen ahí, esperando un desarrollo normativo que no termina de encauzarse. 


\section{El contexto}

Eran los primeros meses de 1995 y se vivía un ambiente de acentuado optimismo en la formación de personas adultas valenciana. Dos meses antes del Seminario, las Cortes Valencianas habían aprobadola Ley 1/95 de 20 de enero, de la Generalitat Valenciana, de formación de personas adultas,una ley que fue considerada modélica en su gestación, redacción y promulgación [1995]. Surgió de una amplia demanda social coordinada por la Mesa de Agentes Sociales para la FPA en el País Valenciano. Se sustentó en las peticiones hechas públicas por decenas de plenos municipales de todo signo político, por centenares de entidades sociales, educativas y culturales, por la práctica totalidad de centros de formación de personas adultas y por miles de personas a título individual. Y se nutrió de intensos debates llevados a cabo por docentes y alumnado participante en los centros públicos de FPA, que vivieron una singular "primavera educativa"llena de posibilidades y esperanzas.

Como profesor de FPA en aquel momento, director de un Centro de referencia (la sede valenciana de la Mesa de Agentes Sociales], miembro activo de la Permanente de la Mesa y asesor en materia de FPA del conseller de Educación de la Generalitat Valenciana, Joan Romero ${ }^{3}$, tuve la fortuna de verme implicado muy activamente en el proceso, viviendo la realidad cotidiana de las aulas y los centros, conociendo las aspiraciones de personas y organizaciones, mediando entre diferentes visiones de la formación de personas adultas, aportando mi propio posicionamiento, participando en la coordinación de los debates y facilitando a los legisladores,para su posible consideración, propuestas concretas y rigurosas de articulado surgidas de las asambleas y reuniones del mundo de la educación de personas adultas valenciana.

La Mesa de los Agentes Sociales por la EPA se había constituido formalmente el 2 de octubre de 1992. ${ }^{4}$ Ese día, representantes de nueve entidades redactaron conjuntamente la Carta de Constitución, que recogía un decálogo reivindicativo sintetizado en el punto décimo: la necesidad de promulgación de una Ley Valenciana de FPA. En la exposición de motivos, se argumentaba que la Mesa se constituía "Ante la situación de la EPA valenciana", necesitada de mayor definición, coordinación e inyección de recursos públicos. Una situación que se había visto agravada,además,"por la desaparición de la Unidad-Programa de EPA dentro del organigrama de la Consellería de Educación".

La Unidad Programa de EPA se había creado a los pocos años de la asunción de competencias educativas por la Generalitat Valenciana, mediante el Decreto 7/1985, de 28 de enero, del Gobierno Valenciano. El Programapretendía, "por una parte, satisfacer, en la medida que lo permitan los recursos presupuestarios al efecto, las necesidades de alfabetización y formación

3 Resolución de 13 de febrero de 1995, del conseller de Educación y Ciencia, por la que se nombra personal eventual ["DOGV" núm. 2458, de 27 de febrero de 1995].

$4 \quad$ El día 2 de octubre de 1992, las nueve entidades fundadoras firmaron la Carta de Constitución, si bien se habían producido reuniones previas para evaluar la situación existente y consensuar las propuestas. Dichas entidades eran la Federación de Asociaciones de Alumnado de EPA, el Taller para la Acción Renovadora de la EPA en el País Valenciano [TAREPA-PV], la Comisión organizadora de los Encuentros [Trobades] de EPA, la coordinadora de profesorado municipal de FPA y las asambleas intercomarcales de profesorado de Castellón, Alicante y Valencia, así como los sindicatos docentes Sindicat de Treballadors de l'Ensenyament del País Valencià [STEPV], y las federaciones de trabajadores y trabajadoras de la enseñanza de Comisiones Obreras [FE-CC.OO.], Unión General de Trabajadores [FETE-UGT] y Confederación General del Trabajo [FE-CGT]. 
permanente de los valencianos para que lleguen a ser ciudadanos participativos en la creación y disfrute de los bienes materiales, culturales y estéticos; por otra parte, establecer criterios objetivos para la selección y especialización del profesorado idóneo para esta peculiar modalidad de enseñanza; $y$, finalmente, articular y sistematizarlas acciones coordinadas con las Diputaciones valencianas en materia de fomento de la Educación Permanente de Adultos".

Desde aquel año 1985, siendo presidente de la Generalitat Joan Lerma y conseller de Educación Ciprià Císcar, la Conselleria de Educación impulsó de manera decidida la creación de centros públicos de educación permanente de adultos en toda la geografía valenciana, y estableció diferentes medidas que permitieron el desarrollo del Programa de EPA: dotación de plantillas al sistema público, subvención a los ayuntamientos para desarrollar programas municipales, coordinación con el programa de EPA de la Diputación de Valencia que venía existiendo desde 1980, celebración de diferentes jornadas formativas, impulso a la innovación educativa, creación de un centro de recursos específico y de asesorías de EPA en los Centros de formación del profesorado [CEPs], experimentación curricular, elaboración de materiales de aula, publicaciones, certámenes literarios... Un equipo entusiasta y eficiente, dirigido por Ma Ángeles [Lina] Herranz, propició la rápida expansión del Programa y acercó la EPA valenciana a los proyectos más dinámicos que se desarrollaban en el Estado y en algunos países europeos. La estabilidad de las plantillas en los centros específicos públicos de EPA y la creación de una red de coordinaciones comarcales propiciaron la generalización de experiencias singulares y activas de EPA y de dinamización social y cultural en todo el territorio valenciano.

También, en el ámbito de la renovación educativa,se constituyó por entonces [octubre de 1984] el Taller para la Acción Renovadora de la Educación Permanente de Adultos del País Valenciano [TAREPA-PV], organización de reflexión-acción pedagógica que participaría activamente en la constitución de la Mesa de Agentes Sociales. Eran tiempos de debate y expansión de la educación de personas adultas en todo el Estado Español, sintetizados en el notable incremento de propuestas formativas públicas y de iniciativa social, en la celebración de las Primeras Jornadas Estatales de Educación de Adultos, en diciembre de 1984 en Madrid;en el impulso a una Coordinadora estatal de colectivos de Educación de Adultos, que fraguaría posteriormente en la Federación de Asociaciones de Educación de Adultos [FAEA], y en la reflexión y redacción de propuestas para la elaboración del Libro Blanco de la Educación de Adultos del Ministerio de Educación.

La revista Papers d'Educació i Cultura, editada por la Conselleria de Cultura, Educación y Ciencia, en su número 6, de abril de 1985, dedicaba la portada y un amplio reportaje a la educación permanente de adultos en la Comunidad Valenciana, a la que se consideraba "en estado de emergencia". Las cifras, verdaderamente, eran preocupantes, como recogía el propio Decreto 7/1985 ya citado ["Todos los anteriores hechos aconsejan, y aún exigen, que constatadas las bolsas de analfabetismo y la creciente demanda de formación permanente de la población en la Comunidad Valenciana, se cree y ponga en marcha un Programa para la Animación y Promoción de la Educación Permanente de Adultos"]. El reportaje de Papers d’Educació i Cultura llevaba firma colectiva [TAREPA-PV] y, como presidente entonces de la entidad, me correspondió coordinar y redactar su contenido y preparar su publicación [TAREPA-PV, 1985].

En pocos años, además de extenderse la red de centros, se multiplicaron las actuaciones de iniciativa pública y social, entre ellas los encuentros["trobades"] de escuelas de adultos, los encuentros comarcales, las semanas culturales colectivas, las jornadas de escuelas de adultos en las ferias del libro, la participación en escoles d'estiu y otras propuestas de los movimientos de 
renovación pedagógica... También se alcanzó una presencia importante del sector en el movimiento sindical, y se logró mayor estabilidad del profesorado municipal, colectivo profesional más numeroso. La formación de personas adultas encontró un importante terreno de intervención en entornos urbanos y rurales, y los Centros de EPA se configuraron como espacios de aprendizaje y convivencia de personas de todas las edades, procedencias, culturas, experiencias y expectativas vitales. Se encontraron también numerosos puntos de visibilidad en medios de comunicación escritos y audiovisuales, locales, comarcales, autonómicos y estatales.

Incomprensiblemente, en 1992, un cambio en la titularidad de la Conselleria de Educación generó la suspensión de la Unidad-Programa de coordinación de las intervenciones en FPA, hecho que generó una sensación de generalizada incertidumbre en el sector. Aunque desde años anteriores ya se habían vivido importantes movilizaciones reivindicativas en el sector y existía documentación en la que se demandaba una Ley valenciana de formación de personas adultas, la nueva situación de dispersión dentro de la propia institución educativa estimuló la iniciativa de coordinación interterritorial de profesorado y alumnado participante y de demanda de una legislación del máximo rango, vindicaciones que fueron canalizadas por la Mesa de los Agentes Sociales por la EPA.

Dos años después de la creación de la Mesa de los Agentes Sociales, y tras una intensa campaña permanente de la que queda amplia constancia en las hemerotecas, las Cortes Valencianas aprueban la Ley 1/95 de 20 de enero, de la Generalitat Valenciana, de formación de personas adultas. La intencionalidad de la Ley valenciana de FPA quedaba expuesta en el preámbulo y en el artículo 1 de la misma: regular la formación de personas adultas en la Comunidad Valenciana y establecer los mecanismos e instrumentos para su estructuración, desarrollo, coordinación y evaluación. Se partía, así, de la necesidad de reglamentar las numerosas y a menudo dispersas propuestas de formación de personas adultas que venían desarrollándose desde distintos ámbitos de intervención, estructurarlas, desarrollarlas, coordinarlas, potenciarlas y evaluarlas.

El Diario de Sesiones de las Cortes Valencianas del 18 de enero de $1995^{5}$ recoge el debate y aprobación en sesión plenaria del dictamen de la Comisión de Educación y Cultura sobre el proyecto de Ley de Formación de Personas Adultas. La Ley fue aprobada por 48 votos a favor, ninguno en contra y 18 abstenciones. Una amplia mayoría de consenso tras el que hubo un importante trabajo de interlocución y mediación por parte de quienes en aquellos momentos coordinábamos el movimiento en favor de la ley, como queda reflejado en las intervenciones de los y las portavoces del parlamento autonómico.

Hemos definido como de eufórico el ambiente que se vivía aquellos meses en la formación de personas adultas valenciana: reuniones, asambleas, jornadas de trabajo, actos formativos y encuentros ponían énfasis en la dinámica de la esperanza que rodeaba las prácticas de la FPA. La VIII Semana Cultural de EPA de la comarca de L'Alacantí, celebrada entre el 13 y el 18 de febrero de 1995, incorporaba a su portada el lema "Nou futur" y añadía a los actos programados una intervención del conseller Joan Romero sobre "El futuro de la educación de personas adultas". En aquel acto, ante varios centenares de personas, Paco Bas, presidente de la Federación Valenciana de Asociaciones de Alumnos de EPA [FEVAEPA] resaltaba en su

$5 \quad$ Corts Valencianes, Diari de sessions. Núm 199, III legislatura, Sessió Plenària celebrada el 18 de gener de 1995. La Ley fue votada favorablemente por los grupos parlamentarios [GP] GP Socialista, GP d’Esquerra Unida y GP d’Unió Valenciana. El GP Popular se abstuvo en la votación. 
intervención el esfuerzo realizado, agradecía su aportación a multitud de entidades y personas, singularmente al propio conseller, y manifestaba su esperanza y la de toda la Federación en un rápido y eficaz desarrollo de la Ley valenciana de FPA. Actos similares se celebraron en Valencia, en Castellón, y en otros municipios valencianos [Alboraia, Torrent, La Vall d’Uixó...].

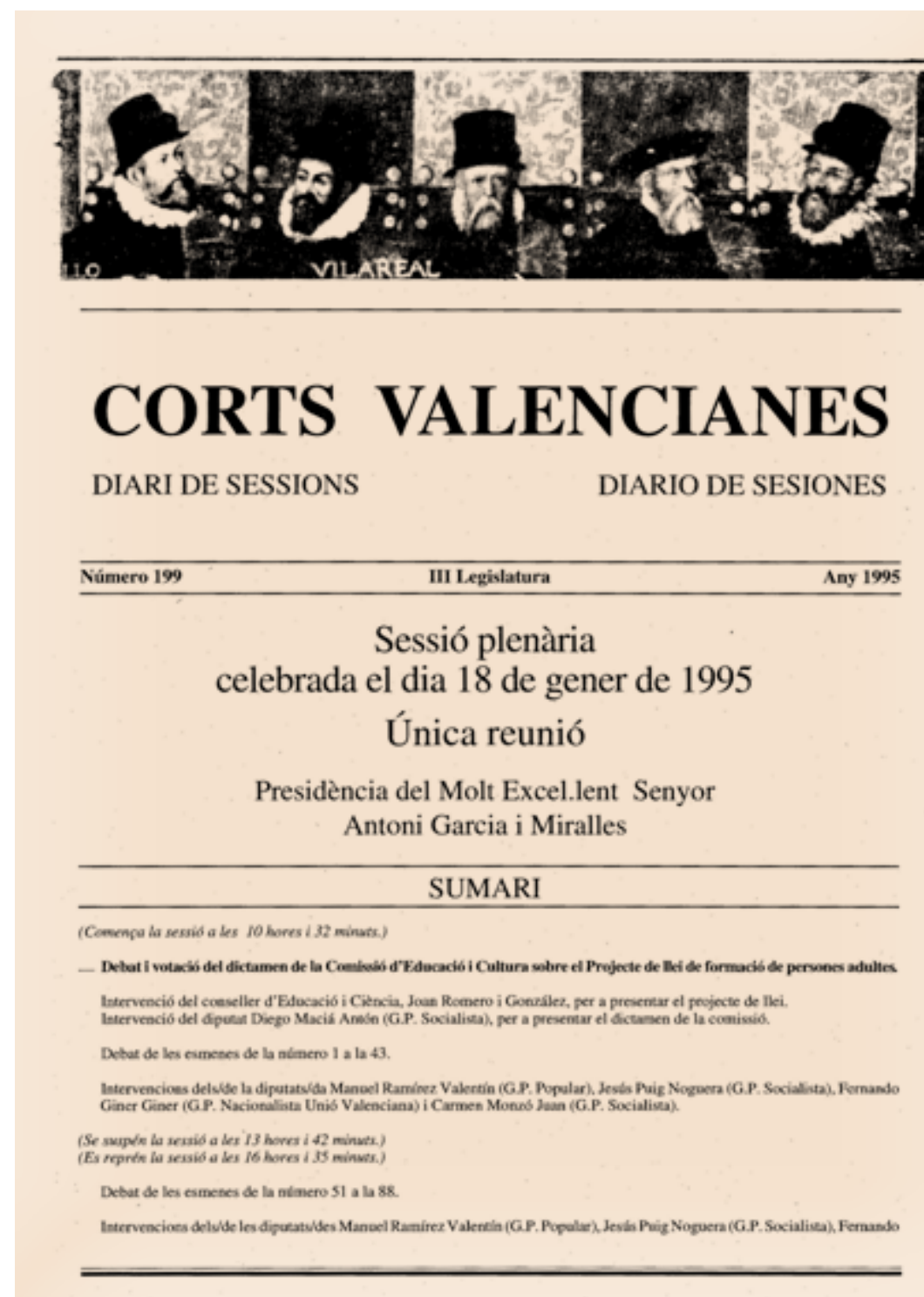

Fig. 3. Portada del Diari de Sessions de les Corts Valencianes de 18 gener de 1995.

La Ley surgió necesitada de un urgente desarrollo. En pocas semanas se publicó la normativa de creación de la Comisión Interdepartamental y del Consejo de la FPA, como organismos de coordinación, planificación e implementación, por un lado, y de participación y asesoramiento, por otro. Se incrementó notablemente la partida presupuestaria destinada a subvencionar a los municipios que desarrollaban proyectos de FPA (de 207 a 500 millones de pesetas en un año] y se procedió también a elaborar un informe sobre la realidad de los edificios que acogían centros públicos de titularidad de la Generalitat, estableciendo las prioridades para un programa de dignificación de los mismos, construyendo nuevos centros y cambiando la ubicación en los 
casos de mayor urgencia. Ello permitió iniciar los trámites para la cesión de suelo municipal en algunas localidades que pudieron contar finalmente con nuevas edificaciones [Giner de los Ríos en Alacant, Sagunt, Mislata, Chiva....

También se aceleraron los trabajos para establecer un nuevo currículum de la FPA en la Comunidad Valenciana, mediante la creación de una comisión asesora de personas expertas y otra comisión técnica de redacción normativa, y se esbozaron numerosas propuestas de desarrollo legislativo que se verían frenadas tras las elecciones autonómicas del 28 de mayo, con una nueva mayoría parlamentaria y el gobierno PP-UV presidido por Eduardo Zaplana6 ${ }^{6}$.

\section{El Seminario}

En el ambiente de esperanza que hemos indicado, se lleva a cabo el Seminario "La importancia estratégica de la formación de personas adultas en la Comunidad Valenciana", dos meses después de la aprobación de la Ley. Los trabajos de organización del Seminario habían comenzado durante el cuarto trimestre de 1994, preparando un programa amplio que integrara las múltiples propuestas que incidían en las prácticas cotidianas de formación de personas adultas, en sus diferentes áreas de intervención: formación básica y acceso a los distintos niveles del sistema educativo; formación para el ejercicio de los derechos y de las responsabilidades ciudadanas, y para la participación social; formación para el desarrollo personal y la participación en la vida cultural; formación ocupacional, orientada al desarrollo profesional que facilite la inserción, la actualización y la promoción laboral; formación social orientada a la inserción, al desarrollo comunitario, a la cohesión social y a la atención de personas adultas con necesidades especiales.

La segunda quincena de diciembre, se había confirmado la presencia de los más de treinta ponentes, organizados en seis conferencias y cuatro foros de reflexión. Las ponencias incluían destacadas aportaciones en el ámbito de la formación de personas adultas, también en el ámbito de las ciencias de la educación en general, de la sociología, de la formación ocupacional, de la gestión pública estatal en FPA, de la gestión política y social valenciana, del sindicalismo, de la empresa y del periodismo. En todos los casos se preveía un periodo de tiempo para que el público asistente pudiera participar en un turno abierto de palabras.

Las seis conferencias planificadas tenían como primer objetivo ofrecer una visión amplia e integradora del fenómeno formación de las personas adultas desde distintos temas, ámbitos y perspectivas, reflejados en los ponentes y los títulos de las ponencias: Paulo Freire ["La naturaleza política de la formación de personas adultas"]; Donaldo Macedo ["Las alfabetizaciones del poder: ¿Qué es lo que se nos permite saber?”]; José Gimeno Sacristán [“Reforma, Universidad, formación de personas adultas"]; Basil Berstein ["Reglas de contextualización del discurso pedagógico"]; Paolo Federighi ["Estrategias para el desarrollo transnacional de la educación de adultos"] y Paul Bélanger ["Políticas europeas de formación de personas adultas: perspectivas para el año dos mil"”?"

$6 \quad$ Tras las elecciones autonómicas de 1995, el Partido Popular de la Comunidad Valenciana y la formación regionalista Unión Valenciana establecieron un pacto de legislatura que iniciaba un periodo de gobiernos conservadores que se prolongaría durante 20 años.

7 Paulo Freire [Universidade de Sao Paulo, Brasil]; Donaldo Macedo [University of Massachussets, USA]; José Gimeno Sacristán [Universitat de València, España); Basil Berstein (Dep. Policy Studies, University of London, Reino Unido]; Paolo Federighi [Università de Firenze, Italia, presidente entonces de la European Association for the Education of Adults -EAEA-]; Paul Bélanger [Director del UNESCO Institute for Education, Hamburg, Alemania]. 
También fueron organizados cuatro paneles de expertos que trataban de aportar diferentes reflexiones sobre otras tantas áreas esenciales en la formación de personas adultas: "Formación y ocupación: estrategias para el desarrollo"; "El desarrollo legislativo en EPA en el Estado Español”; "Formación permanente: vertebración y cambios sociales"; "Formación permanente y desarrollo territorial”. El primero de ellos fue moderado por Gustau Muñoz Veiga, y contó con la presencia de representantes de los agentes sociales y expertos universitarios [José Ginés Mora, Luis Espinosa, Miquel Vilalta, Adalberto Ferrández, y representantes de los sindicatos Comisiones Obreras y Unión General de Trabajadores] ${ }^{8}$. El segundo fue moderado por Ramón G. Flecha y contó con la presencia de altos cargos de distintas comunidades autónomas y del Gobierno Central [Mariano Jabonero, Àngela Miquel, Francisco Contreras, Marino Alduán] .

El tercer panel fue coordinado por Adolf Beltrán, y en él participaron diferentes responsables de departamentos sociales de la Generalitat e investigadores de la Universidad de Valencia [Francesc Morán, Guillem Badenes, Jesús Huguet, Lourdes Alonso, Ernest García] ${ }^{10}$. El cuarto panel fue coordinado por José A. Aparicio [TAREPA-PV] y contó con la participación de investigadores de distintas universidades y organizaciones estatales y trasnacionales de educación de adultos [Paolo Orefice, Manuel Collado, Isidoro Alonso Hinojal, Jaume Obrador, Rosa Må Falgás] ${ }^{11}$.

Una iniciativa atrevida e inusual por entonces en actos similares fue la participación no anunciada de Virginia Imaz, maestra y filóloga, payasa profesional y fundadora de la compañía de Teatro Oihulari Klown, que incluía tras cada sesión del seminario sus propias "klownclusiones" sobre las aportaciones realizadas. En un tono desenfadado, ocurrente, divertido, y nunca hiriente u ofensivo, "la payasa"generó tras cada sesión del Seminario una sana hilaridad entre las personas presentes, de manera singular entre los propios ponentes, sobre cuyas reflexiones "klowncluía". Como ella misma afirmaba, su trabajo consistía en llevar a cabo un proceso de "reeducación" emocional a través del humor.

Como se apuntaba al inicio, en el contexto del mismo Seminario, se llevaron a cabo dos jornadas formativas en la Cámara de Comercio de Castellón y en el Aula de Cultura de la Caja de Ahorros

8 Gustau Muñoz Veiga [Universitat de València y Jefe de Redacción de la revista Debats, -Instituto Valenciano de Estudios e Investigación - IVEI]; José Ginés Mora Ruiz [Universitat de València); Luis Espinosa Fernández [Secretario General de CIERVAL], Miquel Vilalta i Sebastià [Secretario General de la Unió de Llauradors i Ramaders del País Valencià); Adalberto Ferrández Arenaz [Universitat de Barcelona]. Estaba prevista la participación de los secretarios generales autonómicos de Comisiones Obreras -Antonio Montalbán Gámez- y la Unión General de Trabajadores -Rafael Recuenco Montero-, que delegaron en miembros de las respectivas ejecutivas sindicales.

9 Ramón G. Flecha [CREA, Universitat de Barcelona]; Mariano Jabonero Blanco [Subdirector General de Educación Permanente, Ministerio de Educación y Ciencia); Àngela Miquel i Anglarill (Directora General de Formació d'Adults, Generalitat de Catalunya); Francisco Contreras Pérez [Director General de Promoción y Evaluación Educativa, Junta de Andalucía], Marino Alduán Alonso [Viceconsejero de Educación, Gobierno de Canarias].

10 Adolf Beltrán i Català (redactor del diario El País]; Francesc Morán i Anglada [Director General de Formació i Inserció Professional, Generalitat Valenciana], Guillem Badenes i Franch [Director General d’Ordenació i Innovació Educativa, Generalitat Valenciana], Jesús Huguet i Pasqual [Director General de Política Lingüística, Generalitat Valenciana], Lourdes Alonso i Beltza [Directora de l'Institut Valencià de la Dona, Generalitat Valenciana], Ernest García i García [Universitat de València].

11 José A. Aparicio Guadas [profesor del Centre FPA de Xàtiva - TAREPA-PV]; Paolo Orefice [Universitá de Firenze, Italia); Manuel Collado Broncano [Universidad de Sevilla]; Isidoro Alonso Hinojal (Centro de Investigaciones Sociológicas]; Jaume Obrador i Soler [Federación de Asociaciones Estatales de Educación de Adultos], Rosa Mª Falgás i Casanova [European Association for the Education of Adults -EAEA-]. 
del Mediterráneo de Alicante, los días 3 y 4 de abril, respectivamente. En estas jornadas, participaron Paulo Freire, Basil Bernstein y Donaldo Macedo, con intervenciones análogas a las realizadas en la ciudad de Valencia, por deseo expreso de la organización del Seminario. También intervinieron Ana María Araujo Freire ["La importancia estratégica de la formación de personas adultas"] ${ }^{12}$ y José Ramón Flecha García ["La educación de las personas adultas ante el racismo moderno y posmoderno"]. La presentación fue realizada por el Director General de Ordenación e Innovación Educativa, Guillem Badenes, y por las autoridades provinciales de Educación.

En la organización del Seminario participó un amplio grupo de personas vinculadas entonces a la Permanente de la Mesa de Agentes Sociales que, con las reservas lógicas en la gestión de una actividad de aquella envergadura, hicieron sus aportaciones sobre participación, dinámica, espacios y aspectos organizativos cotidianos. También se contó con la colaboración del CREA [Centro de Investigación Social y Educativa, Universidad de Barcelona]. De manera singular, entre otras muchas personas, es preciso mencionar a Neus Debón y Matilde Llop, del Centre Valencià d'Educació d'Adults a Distància (CEVEAD); a Pep Aparicio, de TAREPA-PV;a Ramón Flecha, Juan Jesús Gómez y Mercé Espanya, del CREA; a Josep Lluís Grau y las compañeras y compañeros del Centre FPA Germà Colomy de las diferentes comarcas de Castellón;a Joan Pérez, Juli Bernabé, y las compañeras y compañeros de las EPAs de l'Alacantí y de las comarcas alicantinas;a Félix Sempere y Vicent Reig, de la FPA de Picassent; a Pep Val y Carme Ribelles, de la FPA de Torrent; a Paco Bas, Susana Monllor y Pilar Fuentes, de la FEVAEPA... a Malui Benet, del Gabinet del conseller de Educación; a Juanma Játiva, jefe del gabinete de prensa de la Consellería de Educación, y a Andrés Castillo, fotógrafo del gabinete. Fue también muy remarcable el trabajo desarrollado porLuis Moreno, coordinador general de actividades de la UIMP, junto a su magnífico equipo integrado por Lidia, Mabel, lolanda y Pino...

Una especial colaboradora fue la fotógrafa Carmen Montañana, que realizó un extraordinario y entrañable reportaje fotográfico sobre el Seminario, singularmente sobre la presencia en él de Paulo Freire. Su generosa cesión de los amplios fondos fotográficos que conserva ha permitido añadir a esta efemérides un material profesional de excepcional importancia sobre la presencia de Paulo Freire en Valencia, material al que puede accederse en esta publicación y en la monografía con la transcripción de la conferencia que impartió, publicada también por el Instituto Universitario de Creatividad e Innovaciones Educativas [IUCIE] y accesible a través de su página web.

El excelente trabajo de registro de la UIMP permitió que toda la documentación escrita del Seminario esté disponible y pueda accederse a ella en una monografía publicada por el IUCIE. Existe también una grabación en vídeo VHS de todas las intervenciones, gracias a la cual se ha podido digitalizar y hacer la transcripción de la intervención de Paulo Freire como documento inédito de extraordinario valor pedagógico, que se hace público en el contexto de estas actividades de conmemoración.

La organización y el desarrollo del Seminario generaron no pocas situaciones de apreciable complejidad. Como se ha comentado, el número de solicitudes desbordó las expectativas, y la limitación de aforo generó un cierto malestar en algunos centros de FPA. Este problema se

$12 \quad$ Ana Ma ${ }^{a}$ (Nita) Araujo Freire, Universidade de Sao Paulo [Brasil), esposa de Paulo Freire e investigadora sobre su obra. 
atenuó con la realización de sendas jornadas formativas en Castellón y Alicante, contempladas en el programa del Seminario. También hubo que ajustar los espacios disponibles en el Palau de Pineda. La sede de la UIMP de Valencia disponía entonces de diferentes salas similares para desarrollar actividades formativas simultáneas. La cifra inédita de inscripciones obligó a que se habilitaran todas las salas para acoger a las personas participantes. Inicialmente, la sala I sería la de las ponencias y paneles presenciales, que se proyectarían por circuito interno de televisión a las otras salas. El propio desarrollo del Seminario propició que las ponencias y paneles se realizaran presencialmente en salas diferentes, para tratar de encontrar una cierta equidad en la distribución de actividades presenciales y no presenciales.

En el acto de apertura, se contó con la participación de Paolo Federighi, profesor de la Universidad de Florencia y presidente de la Asociación Europea de Educación de Adultos, y del conseller de Educación de la Generalitat Valenciana, Joan Romero. Este destacó en su intervención el carácter integrador de la formación de personas adultas y vaticinó una importante eclosión de la FPA, por ser objeto de interés creciente en nuestro entorno europeo. Como responsable de la dirección del Seminario, participé en aquel acto de apertura, así como en la presentación de Paulo Freire y Basil Bernstein y en el acto de clausura y de lectura de recomendaciones y conclusiones. Mi breve intervención en el acto inaugural incidió en remarcar que en el Seminario convergían inquietudes, esfuerzos e ilusiones de muchísimas personas vinculadas a la formación de personas adultas en el País Valenciano, así como en subrayar que se buscaba ante todo enriquecer más un mundo que por sí mismo era ya rico y complejo.

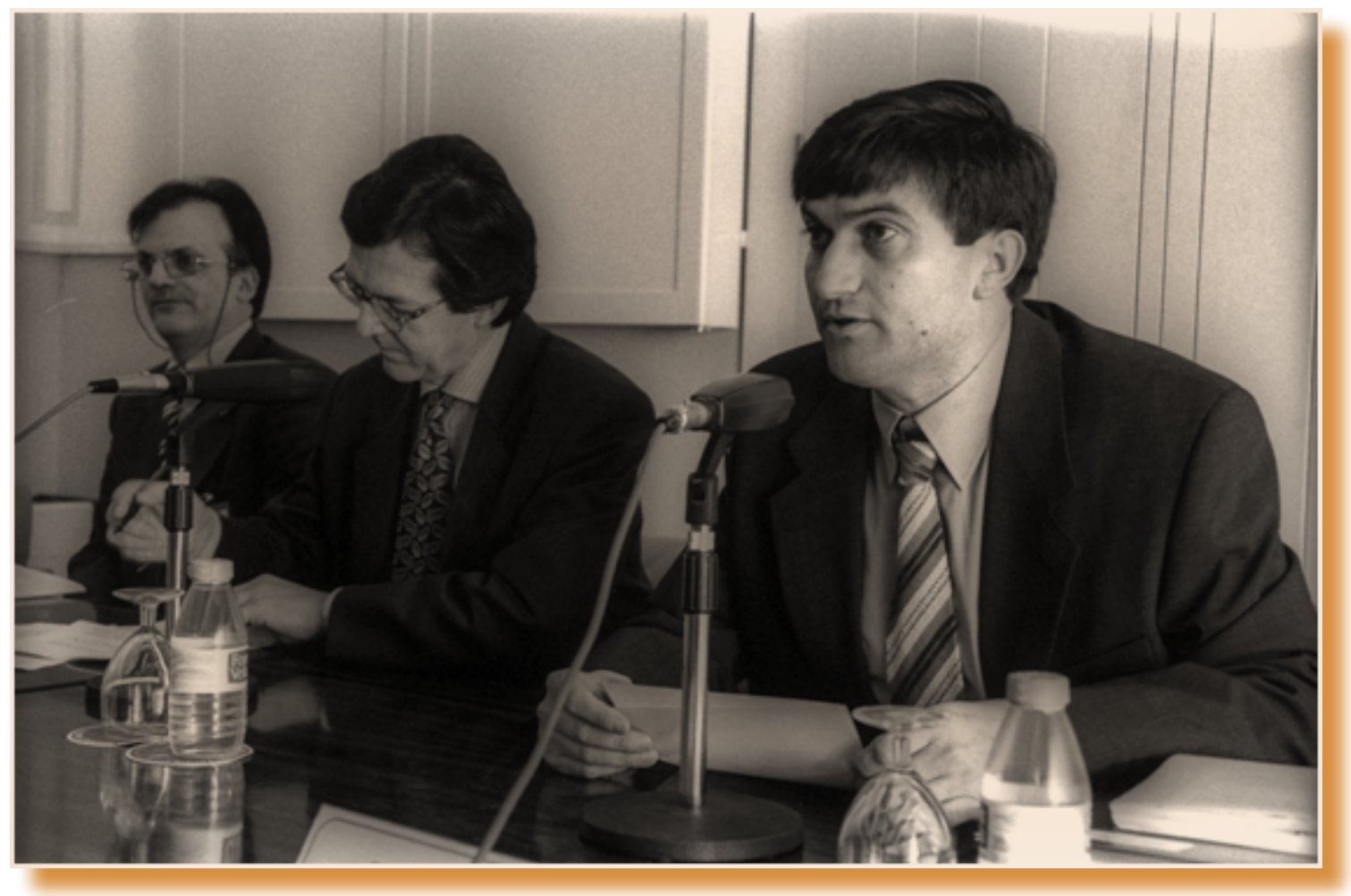

Fig. 4. Acto inaugural del Seminario. Mesa de Inauguración: Paolo Federighi, Joan Romero, José A. Veiga [de izquierda a derecha]. Fotografía original de Carmen Montañana, cedida por la autora.

Las aportaciones del Seminario, a mi entender, fueron remarcables en el proceso iniciado de tratar de establecer y consolidar firmes líneas estratégicas en la formación de personas 
adultas. Se buscaban áreas comunes de intervención en una realidad institucional compacta y compartimentada en la que Educación educaba, Trabajo formaba, Cultura cultivaba y los Servicios sociales atendían, cuando los espacios de intersección entre estas y otras instancias eran totalmente permeables, a los ojos de quienes construíamos el día a día en ellas. Fueron aportaciones destacadas, y su trascendencia habría sido mucho mayor si no se hubiera producido el cerrojazo político al desarrollo de la Ley de FPA tras la regresión en la Generalitat en mayo de 1995.

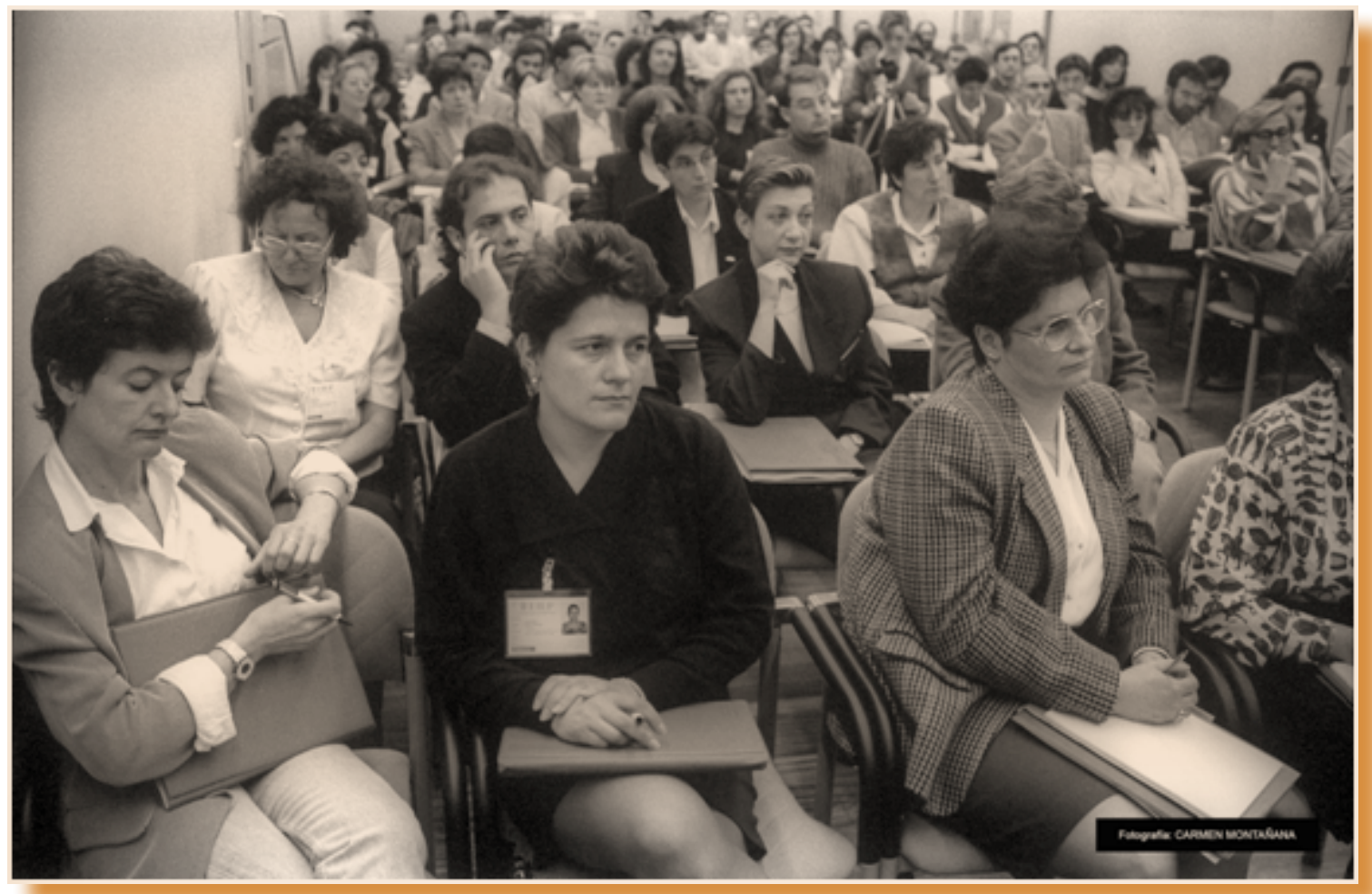

Fig. 5. Público asistente al seminario. Panorámica de la Sala I de la UIMP. Fotografía original de Carmen Montañana, cedida por la autora.

La intervención completa de Paulo Freire ha sido transcrita por Édina de Brito y comentada por José Beltrán Llavador, y a ella puede accederse en el enlace https://youtu.be/unjZ3lzpLVs

Me gustaría resaltar dos aportaciones de esta intervención que estimo fundamentales, omnipresentes en la obra de Freire: su idea de educación como intervención crítica del sujeto frente a la vida, y su visión del trabajo del alfabetizador (del educador de personas adultas, añadiría] como acercamiento y convivencia con la formación cultural de los alumnos, con su identidad cultural, persiguiendo la comprensión crítica de la realidad desde el respeto al propio saber, incluso aunque sea absolutamente ingenuo.

Freire diferencia entre curiosidad común, cotidiana, y curiosidad epistemológica, intelectual. Ambas coexisten y ambas construyen conocimiento. Trabajarlas ofrece múltiples posibilidades. Las personas adultas poseen una propia experiencia de curiosidad espontánea, de sentido común, que puede facilitar la profundización en los saberes críticos, rigurosos. Muchos saberes populares dan respuestas intuitivas a las realidades cotidianas. Pero también muchas veces, los saberes intuitivos llegan a ser saberes ingenuos que conducen a afirmaciones que no se 
corresponden con la realidad. Estas reflexiones sobre el saber ingenuo cobran si cabe mayor actualidad en tiempos y circunstancias como los que ahora vivimos, cuando se ha oficializado la existencia de realidades paralelas, de interpretaciones erróneas muchas veces intencionadas capaces de influir en la toma de decisiones trascendentales en todos los órdenes de la vida.

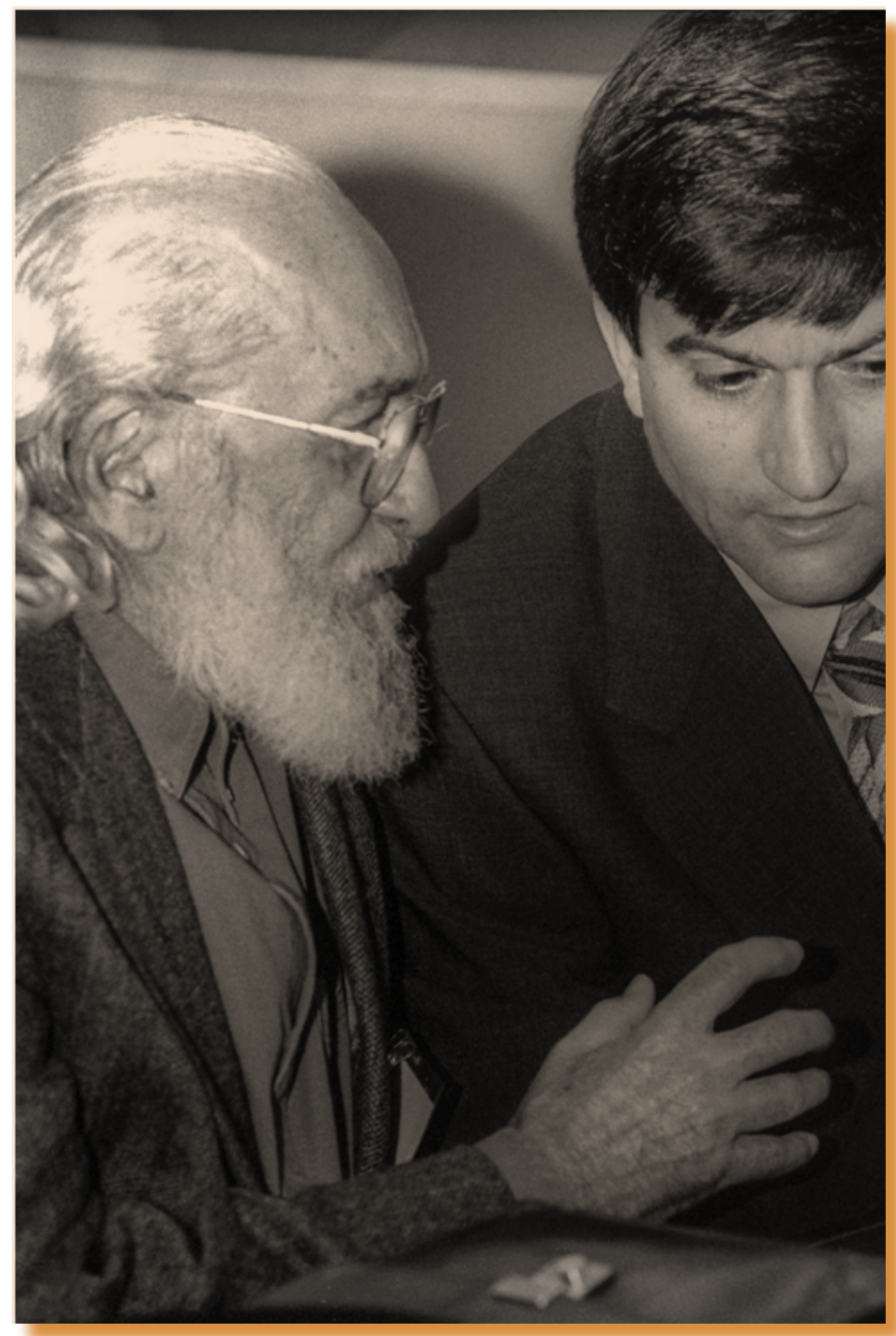

Fig. 6. Intervención de Paulo Freire. Fotografía original de Carmen Montañana, cedida por la autora. 


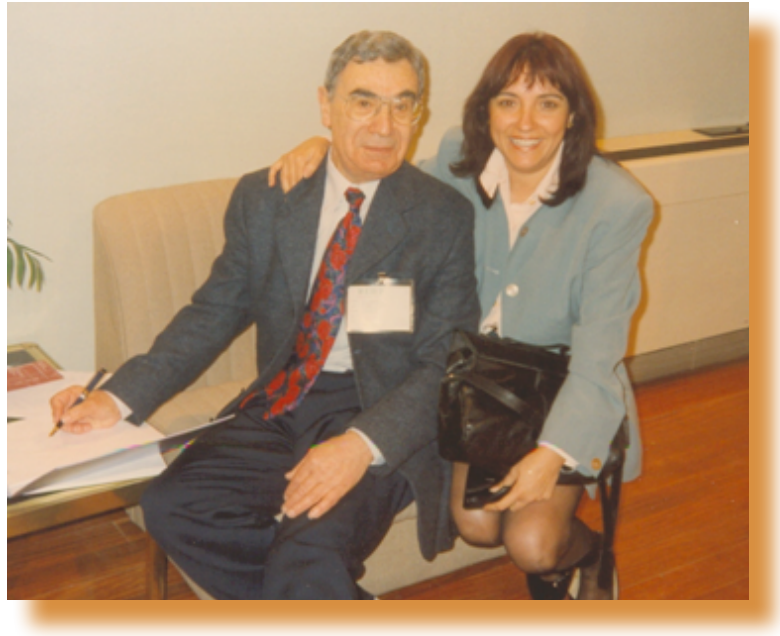

Fig. 8. Virginia Imaz, [Teatro Oihulari Klown]. Junto a los profesores Matilde Llop, Neus Debón y Emiliano Villena. Fotografía cedida por Matilde Llop.
Fig. 7. Basil Bernstein y Matilde Llop. Receso del Seminario. Fotografía cedida por Matilde Llop.

La presencia de Paulo Freire, de Basil Berstein, de Donaldo Macedo y de Ana María Araujo Freire en tierras valencianas no se limitó a sus intervenciones estrictamente académicas. Las actividades en las que participaron se iniciaron el jueves, 30 de marzo, y finalizaron el martes, 4 de abril. Fueron un mínimo de seis los días que compartimos con ellos sesiones de trabajo, y también momentos de descanso y de conversación distendida. Uno de estos momentos fue la comida que organizamos el sábado día 1 de abril, en mi casa, situada a las afueras de la ciudad de Torrent, en el área metropolitana de Valencia.

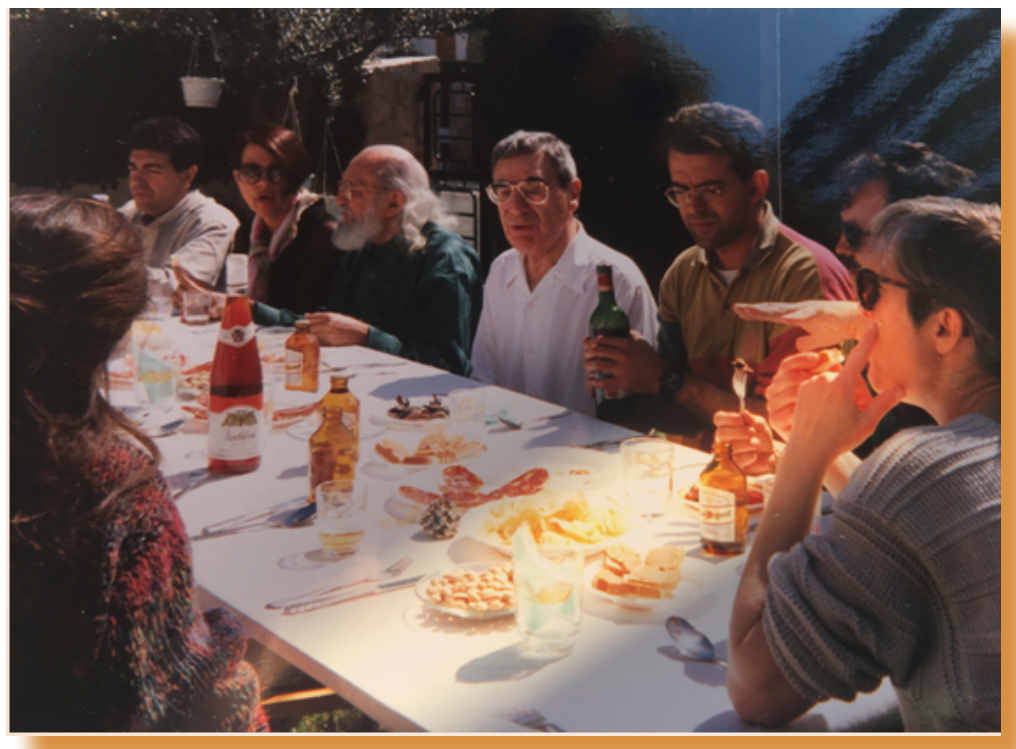

Fig. 9. Comida en Torrent. Foto grupal [1]. Parte del grupo. Centro de la imagen: Nita Araujo, Paulo Freire, Basil Bernstein, Vicent Reig. Fotografía cedida por Matilde Llop.

Aprovechamos un día primaveral, estable y con muy buena temperatura, y también que la casa disponía de patio, y organizamos una "paella" colectiva. Todo surgió de una manera natural, espontánea. Algunas de las personas que colaborábamos en la organización del Seminario preparamos la infraestructura necesaria y citamos a Paulo, a

Nita, a Basil, a Donaldo, a los miembros del CREA Juan Jesús Gómez (Pato], Ramón Flecha y Mercé Espanya, y a diferentes acompañantes de estos y estuvimos varias horas viendo primero cómo se elabora una paella, hablando relajadamente en un contexto ajeno al del bullicio habitual de jornadas y congresos, comiendo un arroz excelente cocinado con leña a la vista de todos por 
Pep Val [jefe de estudios entonces de la EPA de Torrent], y disfrutando de una animada tertulia de sobremesa que se prolongó buena parte de la tarde a la sombra de un olivo y una jacarandá, tal vez inspirando a Paulo en el recuerdo de vivencias infantiles que menciona en sus "Primeras palabras" de A la sombra de este árbol: "Los árboles siempre me han atraído. Las copas redondeadas, la variedad de su verde, la sombra acogedora, el olor de las flores, los frutos, la ondulación de las ramas, más intensa o menos intensa en función de su resistencia al viento. La agradable acogida que sus sombras siempre dan a quien a ellas se acerca, incluso a los pájaros multicolores y cantadores. A los bichos, tranquilos o no, que reposan en ellos" [Freire, 1997).

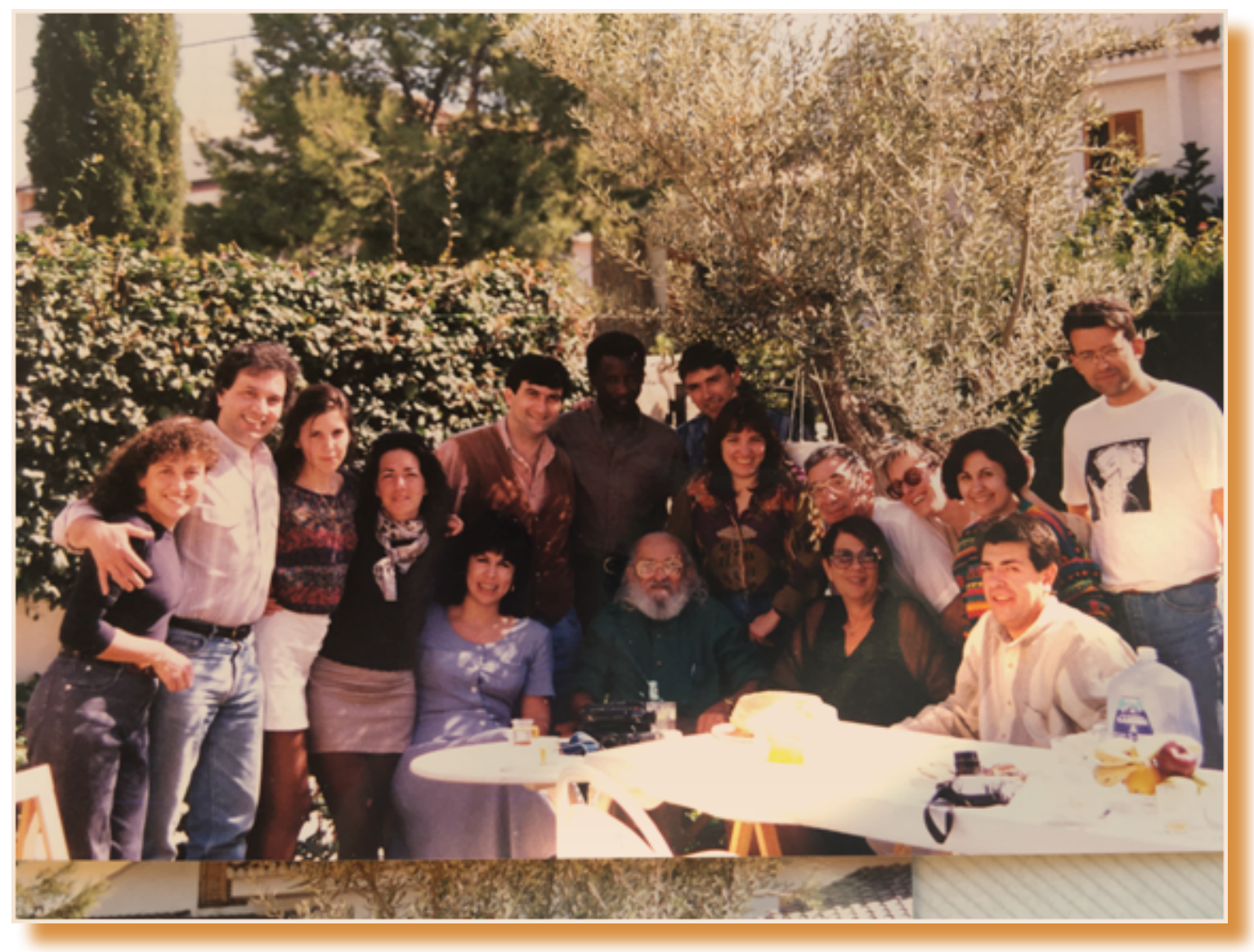

Fig. 10. Comida en Torrent. Foto grupal [2]. Parte del grupo. Entre otros, Donaldo Macedo [segundo por la izquierda], Paulo Freire, Nita Araújo, Basil Bernstein [centro]. Fotografía cedida por Matilde Llop.

Los acompañantes más cercanos a Paulo y a Basil valoraron como muy acertada la propuesta de hacer una comida colectiva, en un entorno sosegado y familiar. Hubo solo una condición que, en cierto modo, todos y todas nos autoimpusimos: que el encuentro fuera en todo momento relajado y se respetara la tranquilidad, evitando en lo posible atosigamientos y exigencias que no correspondían en un día de asueto.

De entre las muchas anécdotas del día, recuerdo con satisfacción los momentos de descanso que Paulo y Basil disfrutaron, sus miradas cálidas y evocadoras; su interés por todo lo que veían; su admiración cuando advertían las distintas fases del proceso de elaboración de la paella [Basil Bernstein hizo un amplio reportaje fotográfico]; su confianza al estar viviendo momentos naturales, sencillos, cotidianos para muchos de los que allí estábamos. Comentamos muchas cosas: sobre la población que nos acogía, sobre las escuelas de adultos en las que trabajábamos 
quienes allí estábamos [Torrent, Picassent, CEVEAD] y sobre el papel de los centros de formación de personas adultas en el territorio valenciano, sobre la situación de desventaja del valenciano en el uso social y en los medios de comunicación, sobre la trobada de escuelas en valenciano que se celebraría al día siguiente en Alboraria, sobre cartografía medieval tras ver una reproducción que conservo del gran Atlas Catalán de Cresques Abraham, sobre la simbología del olivo, árbol de paz y acuerdo, símbolo de salud y longevidad...

Algunos de esos momentos fueron recogidos en instantáneas que transmiten la calidez de las vivencias. Además de la foto de parte del grupo, que se acompaña en este escrito, realizada a la sombra de un olivo, hay dos a las que siempre he tenido un especial apego: en una de ellas, Nita sostiene en sus piernas a una niña que habla con ella y con Paulo de manera tan humana, tan sencilla, tan espontánea, que nos induce a reafirmar una naturaleza entrañable tras una de las personalidades más destacadas de la educación del siglo XX. Aquella niña es hoy la doctora Paula Villena, hija de Mati Llop, y protagoniza una instantánea llena de franqueza y humanidad.

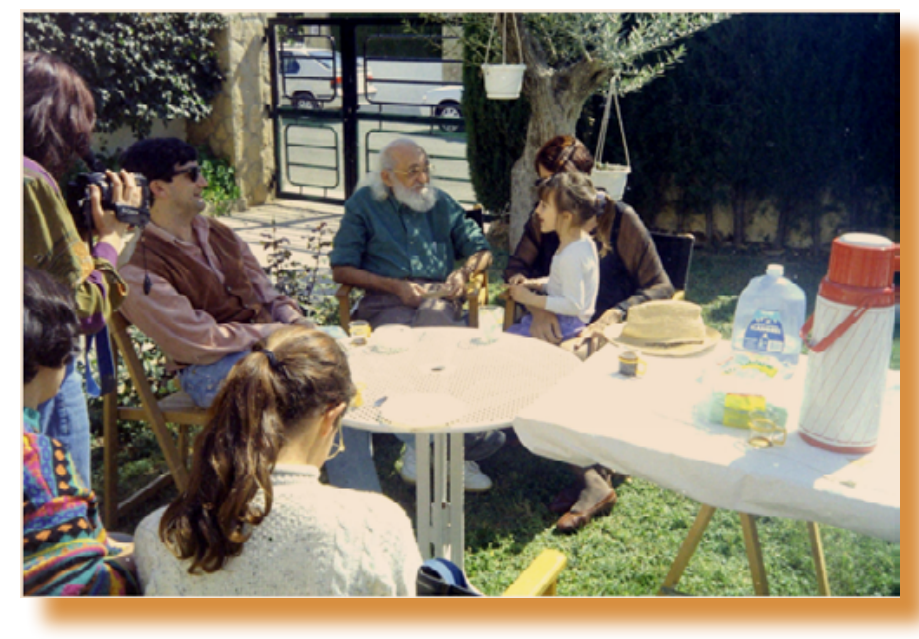

Fig. 11. Comida en Torrent [3]. Paulo Freire, Nita Araújo, Paula Villena. Fotografía cedida por Matilde Llop.

Fig. 12. Comida en Torrent [4]. Basil Bernstein, José A. Veiga, Nadia Veiga. Fotografía cedida por Matilde Llop.

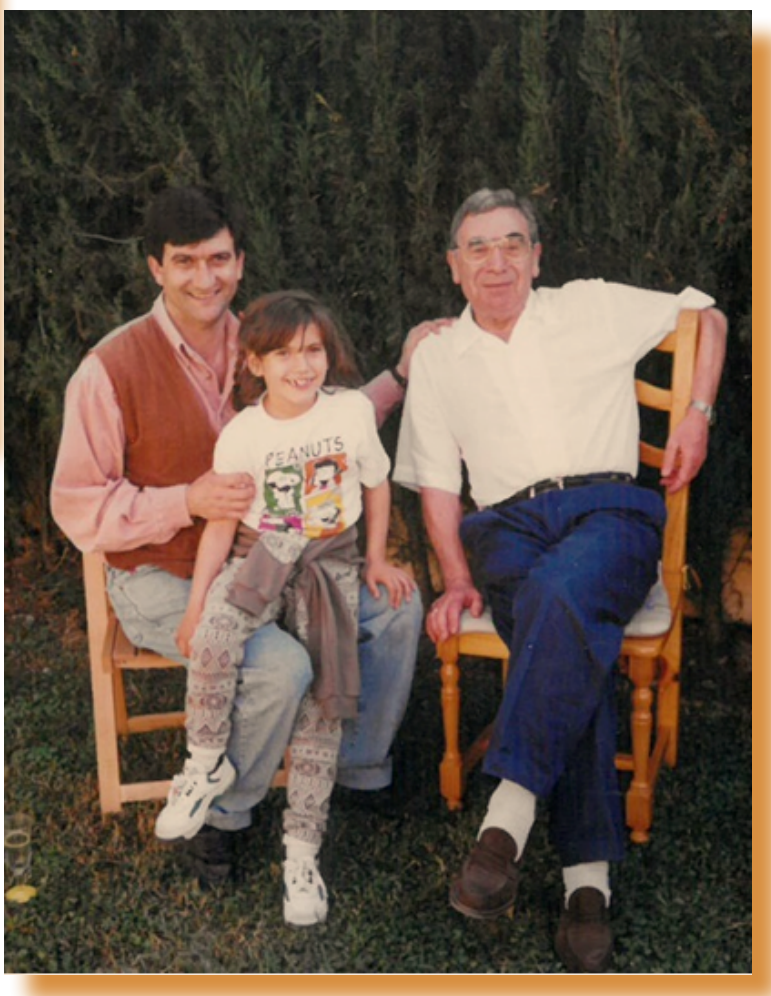

La segunda foto corresponde a Basil Bernstein relajadamente sentado después de la sobremesa, junto a otra de las niñas presentes en la comida, a la que sostengo en mis piernas: se trata de Nadia, una de mis hijas, que aún guarda un débil recuerdo de aquel día en el que compartió palabras con Paulo Freire y Basil Bernstein y los sintió cercanos. Las niñas y los niños presentes en la comida jugaban a subirse a los árboles, y Nadia se recuerda siempre subida al olivo, y viendo a Paulo debajo, sentado, descansando y meditando bajo el árbol, y dirigiéndole unas palabras acerca de la suerte de disponer de un olivo en el patio, para el juego y para el resguardo. 
Tras el Seminario, Paulo tenía que seguir viaje hacia Lausana, en Suiza, y Nita Araujo mostró interés en que se le tomara la tensión arterial. Cerca de allí vivía Teresa Llop, hermana de Mati Llop y médica de Servicio de Asistencia Médica de Urgencias de la Generalitat en el Centro de Salud de Torrent. Teresa se acercó a acompañarnos y le tomó a Paulo la tensión arterial que, efectivamente, estaba alta. Paulo mostró una lógica preocupación, y los demás nos alarmamos... Hasta que la curiosidad que siempre le impulsaba le llevó a preguntar a Teresa muchas cosas relacionadas con la presión arterial, con la fisiología, con la fragilidad del cuerpo humano... También comentó que le había resultado muy cercana y cómoda la toma de tensión por parte de Teresa, una persona siempre jovial y comunicativa, dinámica y habituada al trato empático con pacientes en las situaciones más extremas. Teresa conocía el papel fundamental dePaulo Freire en la educación contemporánea, y le regaló el tensiómetro como recuerdo de aquellos momentos verdaderamente cálidos y entrañables. Una foto de la sobremesa recoge esos instantes, en los que se aprecia la naturalidad, la sencillez y el confort de quienes la protagonizan.

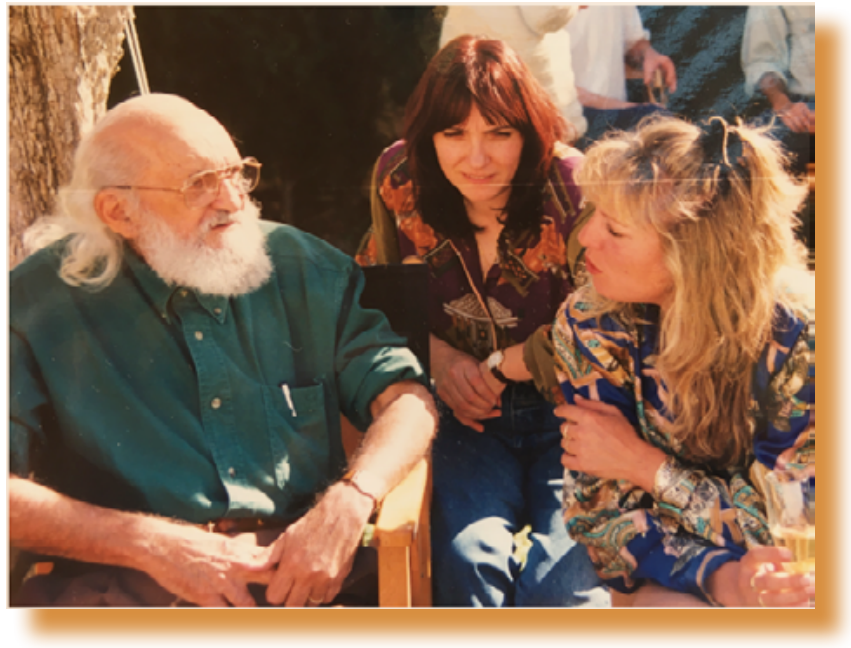

Fig. 13. Comida en Torrent [5]. Paulo Freire, Matilde Llop, Doctora Teresa Llop. Fotografía cedida por Maltilde Llop.

Fueron todas estas, en su día, vivencias llenas de significado. Construíamos nuestras propias historias y cooperábamos en la construcción de la historia colectiva de la formación de las personas adultas valencianas. $Y$ continuamos haciéndolo posteriormente desde nuestros puestos de trabajo, aunque las circunstancias políticas truncaron el proceso esperanzador que se había iniciado.

\section{De la esperanza a la espera: un desarrollo legislativo truncado}

El Seminario se llevó a cabo en un contexto de expectación por la aprobación de la ley valenciana de FPA y los primeros pasos de desarrollo normativo derivado de la misma. Muchas eran las intervenciones necesarias, pero las elecciones del 28 de mayo de 1995 trajeron una nueva mayoría parlamentaria a las Cortes Valencianas y el gobierno surgido del pacto PP-UV auspició una dramática paralización de todo aquello que tanto había costado alcanzar. Dicha paralización supuso, en primer lugar, el retorno a una concepción exclusivamente compensadora de la formación de personas adultas, muy alejada de las que se venían propiciando sobre la materia en todos los foros nacionales e internacionales. Supuso, también, el abandono de la idea de coordinación de recursos y actuaciones, y la renuncia a establecer los mecanismos e instrumentos para su estructuración, desarrollo, coordinación y evaluación. Todo ello condujo a la parálisis inmediata de los dos organismos ya creados, la Comisión Interdepartamental y el Consejo de la FPA.

No se creó un órgano directivo de FPA en la Conselleria de Educación, ni se elaboró el plan general de actuaciones ni el mapa de intervenciones; se paralizó el programa de dignificación de las instalaciones existentes; se disminuyeron los presupuestos destinados a los programas formativos realizados por las corporaciones locales; se paralizó la posibilidad de conformar 
equipos multiprofesionales en los Centros y se fue abandonando progresivamente la idea de formación específica del profesorado de nueva incorporación, más allá de la voluntariosa y encomiable labor de algunos centros de formación del profesorado y entidades sociales. No se elaboró una normativa específica que asegurara y potenciara la participación y el asociacionismo, y se desestimó la demanda de un Convenio General Multilateral para determinar la contribución de la Generalitat en el mantenimiento de las iniciativas formativas de las corporaciones locales y de las entidades titulares de centros de iniciativa social. Tampoco se reguló la creación de los Consejos locales y territoriales de Formación de Personas Adultas para el establecimiento y desarrollo de Planes de acción local y supramunicipal.

Así y todo, al amparo de la Ley valenciana de FPA, los Centros públicos de formación de personas adultas han venido realizando una magnífica labor educativa, formativa, social y humana. Han sido miles y miles los valencianos y las valencianas que en ellos han aprendido a leer y escribir, han aumentado su formación general, han obtenido titulaciones básicas o profesionales, han accedido a estudios superiores, se han alfabetizado en la propia lengua, han estudiado otros idiomas, se han familiarizado con los usos de las nuevas tecnologías y han realizado una gama amplísima de cursos y talleres ocupacionales y de ocio creativo. Todo ello ha permitido mejorar las expectativas personales y profesionales, ha incidido muy positivamente en la convivencia en nuestros barrios y pueblos, y ha posibilitado, en suma, el desarrollo de la "capacidad para juzgar críticamente y participar activamente en la realidad cultural, social y económica”, como sostiene la Ley.

Han transcurrido ya veinticinco años desde que se aprobó la Ley. Ha habido un nuevo cambio político en la Generalitat, que ha permitido el acceso al gobierno autonómico de las fuerzas políticas progresistas $^{13}$.La Ley valenciana de FPA continúa vigente, esperando un pleno desarrollo que, desde mi punto de vista, permitiría la mayor coordinación de actuaciones y recursos relacionados con la intervención social, educativa, laboral y cultural, desde una perspectiva de aprendizaje a lo largo de toda la vida. La European Association for the Education of Adults - [Asociación Europea para la Educación de Adultos], en su Manifiesto para el aprendizaje de adultos en el siglo XXI, proclama que la educación y formación a lo largo de toda la vida permite hacer frente con mayor nivel de éxito a los retos que se plantean en el proceso de construcción de una auténtica sociedad del conocimiento: ciudadanía activa y democrática; cohesión social, equidad e igualdad; habilidades para la vida; ocupación y trabajo; cultura; salud y bienestar; digitalización; migraciones y cambios demográficos; sostenibilidad; conciencia europea; multilingüismo ${ }^{14} \ldots$

Hemos comentado anteriormente que la situación formativa ha mejorado en las últimas décadas, pero no dejan de ser preocupantes los datos actuales de fracaso escolar y abandono educativo temprano, los menguados índices de competencias en comprensión lectora y comprensión matemática de la población adulta, las cifras de población mayor de 18 años con formación en un nivel inferior a la secundaria posobligatoria, y también la nada desdeñable presencia de un nuevo analfabetismo real y funcional, alimentados por el fracaso temprano en el sistema educativo y

13 En 2015, tras las elecciones autonómicas del 24 de mayo, el PSPV-PSOE, Compromís y Podemos establecieron las bases programáticas de un cambio progresista en la Generalitat Valenciana, que serían renovadas tras las elecciones autonómicas del 27 de mayo de 2019.

14 European Association for the Education of Adults - EAEA: Manifest for Adult Learning in the 21st century: The Power and Joy of Learning. 2019. 
por los fenómenos migratorios, tal y como se percibe ya en los centros públicos de FPA, con importantes demandas de población migrante joven que desconoce oralmente y por escrito las lenguas oficiales valencianas y, también, en ciertos casos, la lengua propia escrita.

Entiendo que, como hace veinticinco años, sería fundamental la reactivación decidida de los órganos de coordinación y participación establecidos en la Ley [Comisión Interdepartamental y Consejo de la FPA]. También propiciar otros aspectos fundamentales no desarrollados: crear un órgano directivo de la FPA, elaborar un plan general de actuaciones y un mapa de intervenciones; dignificar urgentemente las instalaciones existentes; aumentar los presupuestos; conformar equipos multiprofesionales en los Centros, revisar los sistemas de provisión de plazas docentes y optimizar el modelo de formación del profesorado; desarrollar una normativa concreta que asegure y potencie la participación y el asociacionismo; establecer un Convenio General Multilateral para determinar la contribución de la Generalitat en el mantenimiento de las iniciativas formativas de las corporaciones locales y de las entidades titulares de centros de iniciativa social; impulsar los Consejos locales y territoriales de FPA y los Planes de acción local y supramunicipal; crear centros integrados de formación básica, profesional, social, cultural y cívica; incrementar la transparencia informativa sobre los datos existentes; instituir un banco de buenas prácticas...

La Ley 1/95 de formación de personas adultas surgió de un proceso de debate colectivoque tambiénpropició la realización de un Seminario en el que se contó con aportaciones de extraordinario valor. En todo aquel proceso, en la propuesta legislativa y en el propio Seminario, se perseguía hacer frente a los retos del futuro desarrollando estrategias formativas coordinadas que incluyeran la educación obligatoria, la postobligatoria, la formación para el empleo, la formación social y ciudadana, la formación humana y cultural y la formación integradora desde el reconocimiento de las diversidades.

La tarea no era fácil, porque no era fácil generar consensos y desarrollar prácticas que pudieran conducir a modificar estructuras administrativas consolidadas, que contaran con la aceptación e implicación de los agentes sociales y que generaran sinergias ilusionantes en todos los implicados. La dificultad de entonces es la de hoy, y los retos siguen estando muy presentes. ¿Utópico? Tal vez. Paulo Freire afirmaba que "La utopía es la reinvención de las sociedades, en el sentido de hacerlas más humanas, menos feas, en el sentido de transformar la fealdad en belleza. La utopía posible es trabajar para hacer que nuestras sociedades sean más vivibles, más deseables para todo el mundo [...]" [Freire, 2003).

\section{Referencias}

Decreto 7/1985, de 28 de enero, del Gobierno Valenciano, por el que se crea el Programa para la Animación y Promoción de la Educación Permanente de Adultos en la Comunidad Valenciana. Diari Oficial Generalitat Valenciana, núm. 229 de 21 de febrero de 1985.

Freire, P. [1997]. Pedagogía de la autonomía. Madrid: Siglo XXI. (1ª edición en castellano].

Freire, P. [1997]. A la sombra de este árbol. Barcelona: El Roure, 1997 [1a edición]. Con Introducción de Ramón Flecha y notas de Ana María Araújo Freire. 
Freire, P. [2003]. El grito manso. Buenos Aires: Siglo XXI.

Ley 1/95 de 20 de enero, de la Generalitat Valenciana, de formación de personas adultas. Diari Oficial Generalitat Valenciana, núm. 2439, de 31 de enero de 1995; Boletín Oficial del Estado, núm. 47, de 24 de febrero de 1995.

Resolución de 13 de febrero de 1995, del conseller de Educación y Ciencia, por la que se nombra personal eventual. Diari Oficial Generalitat Valenciana, núm. 2458, de 27 de febrero de 1995.

TAREPA-PV [1985]. La educación de adultos, en estado de emergencia. Papers d'Educació $i$ Cultura, 6. Conselleria de Cultura, Educación y Ciencia. Generalitat Valenciana 1,3-5. 